Review Article

\title{
Biochemistry, Safety, Pharmacological Activities, and Clinical Applications of Turmeric: A Mechanistic Review
}

\author{
Rabia Shabir Ahmad (D), Muhammad Bilal Hussain $\left(\mathbb{D},{ }^{1}\right.$ Muhammad Tauseef Sultan $\left(\mathbb{D},{ }^{2}\right.$ \\ Muhammad Sajid Arshad (D), ${ }^{1}$ Marwa Waheed, ${ }^{1}$ Mohammad Ali Shariati $\left(\mathbb{D},{ }^{3}\right.$ \\ Sergey Plygun, ${ }^{3,4,5}$ and Mohammad Hashem Hashempur $\mathbb{D}^{6,7}$ \\ ${ }^{1}$ Institute of Home and Food Science, Government College University, Faisalabad 38000, Pakistan \\ ${ }^{2}$ BZU, Multan 66000, Pakistan \\ ${ }^{3}$ Laboratory of Biocontrol and Antimicrobial Resistance, Orel State University Named after I.S. Turgenev, Orel 302026, Russia \\ ${ }^{4}$ European Society of Clinical Microbiology and Infectious Diseases, Basel 4051, Switzerland \\ ${ }^{5}$ All Russian Research Institute of Phytopathology, Moscow 143050, Russia \\ ${ }^{6}$ Noncommunicable Diseases Research Center, Fasa University of Medical Sciences, Fasa, Iran \\ ${ }^{7}$ Department of Traditional Persian Medicine, Fasa University of Medical Sciences, Fasa, Iran
}

Correspondence should be addressed to Muhammad Bilal Hussain; itsmee1919@gmail.com and Mohammad Hashem Hashempur; hashempur@gmail.com

Received 30 November 2019; Revised 4 March 2020; Accepted 16 April 2020; Published 11 May 2020

Academic Editor: Gioacchino Calapai

Copyright (c) 2020 Rabia Shabir Ahmad et al. This is an open access article distributed under the Creative Commons Attribution License, which permits unrestricted use, distribution, and reproduction in any medium, provided the original work is properly cited.

Turmeric (Curcuma longa L.) is a popular natural drug, traditionally used for the treatment of a wide range of diseases. Its root, as its most popular part used for medicinal purposes, contains different types of phytochemicals and minerals. This review summarizes what is currently known on biochemistry, safety, pharmacological activities (mechanistically), and clinical applications of turmeric. In short, curcumin is considered as the fundamental constituent in ground turmeric rhizome. Turmeric possesses several biological activities including anti-inflammatory, antioxidant, anticancer, antimutagenic, antimicrobial, antiobesity, hypolipidemic, cardioprotective, and neuroprotective effects. These reported pharmacologic activities make turmeric an important option for further clinical research. Also, there is a discussion on its safety and toxicity.

\section{Introduction}

Functional foods have been used traditionally for medicinal purposes through history $[1,2]$. In recent decades, there is an increasing interest in research on functional foods and dietary supplements for different diseases [3-6]. Turmeric is one of the most popularly investigated functional foods [7]. Turmeric (Curcuma longa L.; syn.: Curcuma domestica Valeton) belongs to the Zingiberaceae family and is extensively cultured in the tropical areas of Asia [8]. Alternative names frequently used for turmeric are turmeric root and yellow root. It generally attains a height of 3-5 feet and has oblong leaves with yellowish funnel-shaped flowers. $C$. longa can be grown in diverse environmental situations at a temperature of $20-35^{\circ} \mathrm{C}$ with yearly rain of $1500 \mathrm{~mm}$. It grows in well-drained sandy or clay loam soils, having a $\mathrm{pH}$ of 4.5-7.5 with good organic status, where it flourishes outstandingly [9].

Turmeric has a long antiquity for its use as a spice in cuisines of Asian countries and also in other areas, globally. For example, it is known as Zard choobe in Persian. It enhances the flavor and improves the color tonality of foods like rice, yogurt, and chicken. However, consumers prefer to use it with other spices to enrich the flavor. Several communities across the globe use turmeric and its variant fractions to formulate certain traditional medications to cure human ailments with especial reference to China, India, Iran, and Indonesia. Turmeric has long been utilized as a tonic. It is also used for a wide variety of diseases including dyslipidemia, stomach disorders, arthritis, and hepatic 
diseases [10-12]. Curcumin (1,7-bis(4-hydroxy-3-methoxyphenyl)-1E,6E-heptadiene-3,5-dione or diferuloyl methane) is a polyphenol derived from the turmeric. Curcumin is a yellow tincture, which can be obtained from the rhizome of the plant [13]. Yellow color of turmeric is owing to the existence of curcumin, which consists of three main curcuminoid complexes: curcumin I, curcumin II, and curcumin III [14]. The dehydrated root portion of turmeric holds up to $8 \%$ curcumin [15]. Curcumin is insoluble in water and ether, but it has the ability to disperse in ethanol and other organic solvents [16]. The diferuloylmethane and volatile oils are other main active ingredients of turmeric. Turmeric has been mentioned to have numerous biological effects including anti-inflammatory, antimicrobial and antitumoral activity, antioxidant, and hypolipidemic properties [17-21]. Furthermore, turmeric has also been reported as a protective agent against various cancers. Figure 1 represents a schematic view about turmeric's medicinal attributes regarding some of the most important mechanisms. It has been proved that curcumin (as the main active ingredient of turmeric) is a potent natural remedy against the process of inflammation and oxidation, thus making it possible to be used as a protective tool for cancer prevention [22-27]. Moreover, turmeric oil contains essential fatty acids showing antifungal, antimutagenic, and antibacterial activities $[28,29]$.

In the current review, nutritional value, the most used products of turmeric, and its biochemistry are briefly discussed. Moreover, there was an attempt not only to highlight the anticancer potential of the turmeric and its components but also to discuss other pharmacological activities by mechanistic details, clinical applications, and safety of turmeric.

\section{Nutritional Composition}

Turmeric is a rich source of carbohydrates and fiber. Also, it contains some proteins and fats, but there is no cholesterol in it. Furthermore, it contains pyridoxine, vitamin C, potassium, calcium, magnesium, and phosphorous in appropriate amounts, making it one of the nutritionally rich natural food products. Table 1 displays the brief nutritional composition of turmeric [30].

\section{Main Products}

Table 2 briefly shows the widely used products of turmeric and their brief descriptions and uses in daily life [31].

\section{Molecular Constituents}

Turmeric has numerous molecular constituents, each possessing a variety of biological activities. For instance, there are a minimum of 20 molecules that are antibiotic and 14 of its constituents have known cancer preventive activity. Also, 12 of its molecules are antitumor, and the other 12 molecules have anti-inflammatory effects. It contains at least 10 molecular constituents with antioxidant properties, too. Overall, 326 biological activities of turmeric are

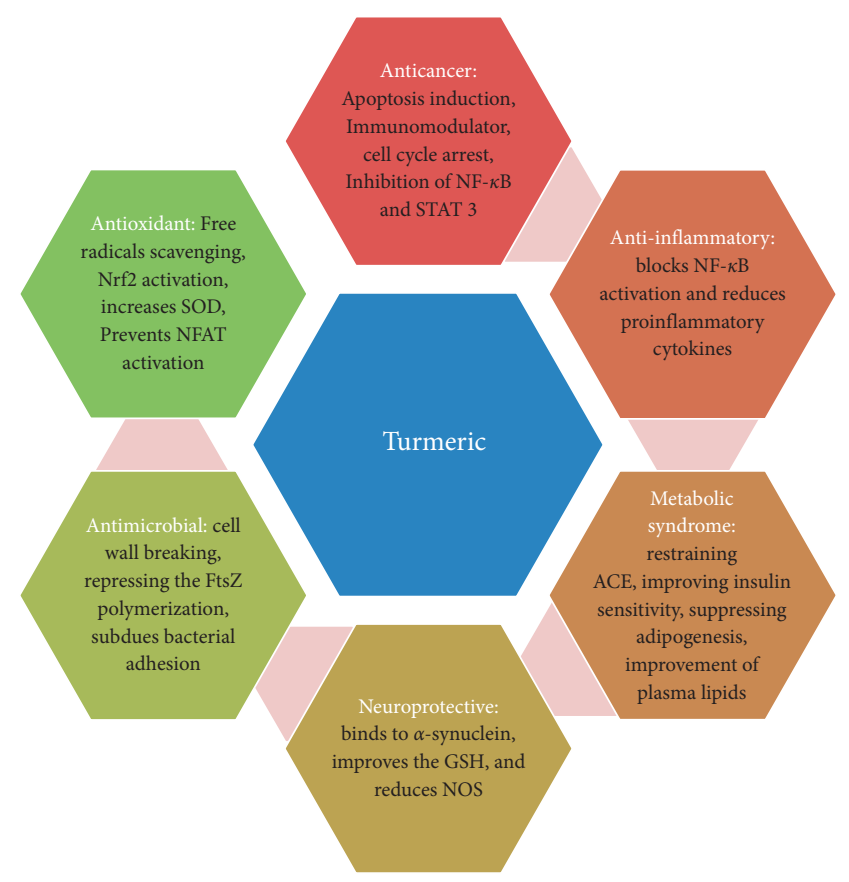

FIgURE 1: A schematic diagram representing turmeric's medicinal attributes regarding some of the most important mechanisms. NF$\kappa \mathrm{B}$ : nuclear factor- $\kappa \mathrm{B}$; STAT3: signal transducer and activator of transcription 3; Nrf2: nuclear factor erythroid 2-related factor 2; SOD: superoxide dismutase; NFAT: nuclear factor of activated T cells; FtsZ: filamenting temperature-sensitive mutant Z; GSH: glutathione; NOS: nitric oxide synthase; ACE: angiotensin-converting enzyme.

identified. Three of the constituents that are widely researched in turmeric are gold-colored alkaloids curcuminoids, namely, curcumin, bisdemethoxycurcumin, and demethoxycurcumin. Figure 2 shows the natural metabolites of curcumin.

\section{Anticancer Perspectives}

In prehistoric times, C. longa has been utilized for the management of numerous illnesses [32, 33]. Turmeric and its ingredient can be considered as multitargeted phytochemicals for cancer treatment. For example, apoptosis, autophagy, and cell cycle arrest can be affected by their use [34]. There are so many signaling pathways (e.g., p53, Ras, phosphoinositide 3- kinase, AKT, Wnt/ $\beta$-catenin, and mammalian target of rapamycin) that are anticancer targets of curcumin $[35,36]$. Also, regulation of microRNAs network expression is modified by turmeric [37]. It should be noted that histone deacetylases activity is inhibited by curcumin, according to in vitro and in vivo studies [38].

5.1. Colorectal Cancer. In recent times, colorectal cancer (CRC) has become an alarming universal health care issue. Data show that obesity and its associated metabolic troubles are linked with colorectal carcinogenesis. Numerous biological mechanisms on the relationship between obesity and the progression of CRC have been established. Insulin 
TABLE 1: Nutritional composition of turmeric.

\begin{tabular}{lcc}
\hline $\begin{array}{l}\text { Principle } \\
\text { constituents }\end{array}$ & $\begin{array}{c}\text { Nutrient value } \\
(\mathrm{kcal})\end{array}$ & $\begin{array}{c}\text { Percentage of RDA } \\
(\%)\end{array}$ \\
\hline Energy & 354 & 17 \\
Carbohydrates & 64.9 & 50 \\
Total fat & 9.88 & 33 \\
Protein & 7.83 & 14 \\
Cholesterol & 0 & 0 \\
Dietary fiber & 21 & 52.5 \\
Vitamins & & \\
Pyridoxine & 1.80 & 138 \\
Folates & 39 & 10 \\
Niacin & 5.140 & 32 \\
Riboflavin & 0.233 & 18 \\
Vitamin A & 0 & 0 \\
Vitamin C & 25.9 & 43 \\
Vitamin E & 3.10 & 21 \\
Vitamin K & 13.4 & 11 \\
Electrolytes & & \\
Potassium & 2525 & 54 \\
Sodium & 38 & 2.5 \\
Minerals & & \\
Manganese & 7.83 & 340 \\
Calcium & 183 & 18 \\
Copper & 603 & 67 \\
Iron & 41.42 & 517 \\
Magnesium & 193 & 48 \\
Phosphorus & 268 & 38 \\
Zinc & 4.35 & \\
\hline
\end{tabular}

resistance and alteration in the insulin-like growth factor-1 (IGF-1) contribute to obesity-related colorectal carcinogenesis [39, 40]. It is also noted that the level of tumor necrosis factor- $\alpha$ (TNF- $\alpha$ ) increases in adipose tissue, which is associated with stimulation of tumor endorsement and development of carcinogenesis [41]. Adipocytokine disproportion and chronic inflammation related to obesity increase the chances of CRC. Curcumin might be an expedient remedy in the prevention of CRC in obese individuals. In fact, it stimulates AMP-activated kinase by lessening the appearance of $\mathrm{COX}-2$ protein and represses the nuclear factor- $\kappa \mathrm{B}(\mathrm{NF}-\kappa \mathrm{B})$ action on the mucosa of the colon. Curcumin also diminishes the leptin concentration in the serum which conversely increases the adiponectin level [42]. According to another study, poloxamer 407 can be used as a polymer for the expansion of colorectal medication liberation system for curcuminoids in CRC treatment [43].

Turmeric performs antitumor and anticancer functions through the inhibition of NF- $\kappa$ B establishment and downregulation of NF- $\kappa \mathrm{B}$-related gene products associated with endurance, propagation, and metastasis of cancer cells. The spice censors the commencement of signal transducer and activator of transcription 3 (STAT3) and stimulates the death receptors. Also, turmeric improves the creation of reactive oxygen species (ROS) and decreases the expansion of tumor cell lines. Furthermore, turmeric increases the sensitivity of the tumor cells to capecitabine and taxol (chemotherapeutic drugs). It also subdues NF- $\kappa \mathrm{B}$ activation initiated by receptor activator of nuclear factor-kappa $B$ ligand (RANKL), which may be associated with the repression of osteoclastogenesis. Hence, turmeric can efficiently obstruct the proliferation of tumor cells by the suppression of NF- $\kappa$ B and STAT3 pathways [44-46]. Furthermore, turmeric can succeed in dealing with the challenge of P-glycoprotein-mediated multidrug resistance of CRC, as exhibited in vitro and in vivo [47].

5.2. Renal Cancer. Long-run exposure of a human kidney cell line to $10 \mu \mathrm{M}$ curcumin changes the swelling-activated chloride current in a dose-dependent way. Curcumin application induces apoptosis in the human kidney cells and stimulates the emergence of a subpopulation of the cells with amplified volume at a concentration of 5.0-10 $\mu \mathrm{M}$. Likewise, $50 \mu \mathrm{M}$ curcumin initiates apoptosis and enlarges the size of colorectal adenocarcinoma cells. The cell cycle arrest might be the reason that increases the size of the cell line after exposure to curcumin [48].

5.3. Hepatic Cancer. In another research, $\mathrm{Yu}$ and colleagues studied the molecular mechanisms of apoptosis induction in human hepatoma SMMC-7721 cells. They reported that curcumin prevents the growth of SMMC-7721 cells appreciably by inducing the apoptosis through the modulation of bax/bcl-2 [49]. It seems that curcumin targets the spindle assembly checkpoint to initiate apoptosis in the cells having higher concentration of phosphorylated cell division cycle 27 (CDC27). Phosphorylation of CDC27 is actually the mechanism by which curcumin exerts its anticancer effect. Curcumin causes cell death by stimulating apoptotic pathway and inhibiting the cell growth and proliferation [50].

5.4. Bone Cancer. Dennis and coworkers demonstrated a novel skylight in amalgamation treatment by exploiting a synthetic analogue of natural compound pancratistatin with the curcumin, for the management of osteosarcoma [51]. Although curcumin has strong antiproliferative and antiinflammatory properties, its low water solubility limits its uses. One controlled study described the preparation and characterization of nanocurcumin using poly-lactic-coglycolic acid. It seems that water solubility and antitumor activity of the mentioned nanoparticulate formulation significantly improved [52].

5.5. Lung Cancer. C. longa is presently labeled to own tumor inhibiting gears not only in vitro but also in vivo. It has been testified that curcumin can progress the tumor hindering efficiency of docetaxel in lung cancer. Likewise, synchronized administration of curcumin and docetaxel results in slight toxicity to normal tissues as well as the bone marrow and liver [53].

5.6. Blood and Other Cancers. Additionally, curcumin is able to repress the growth of a variety of malignant cell types together with the lymphoma cells. The treatment of Burkitt's lymphoma cell lines with curcumin in combination with 
TABle 2: The main products of turmeric, their descriptions, and uses.

\begin{tabular}{|c|c|c|}
\hline Product name & Description & Uses \\
\hline $\begin{array}{l}\text { Whole rhizome } \\
\text { (dried form) }\end{array}$ & $\begin{array}{l}\text { Appearance: orange-brown, red-yellow, or pale yellow } \\
\text { Chemical composition: it may contain } 3-15 \% \text { curcuminoids, and } 1.5 \text { to } 5 \% \\
\text { essential oils } \\
\text { Preparation: finger rhizomes and mother rhizomes are generally boiled, separately } \\
\text { for about } 40-60 \text { min, under slightly alkaline conditions. It should be followed by } \\
\text { sun-drying for } 10-15 \text { days to diminish the moisture content about } 10 \%\end{array}$ & Medicinal purposes \\
\hline Ground turmeric & $\begin{array}{l}\text { Appearance: either yellow or red-yellow in color } \\
\text { Chemical composition: the main active ingredients (i.e., curcuminoids and } \\
\text { essential oils) may lessen during the process and also by exposure to light. It is } \\
\text { necessary to pack the powder in a UV protective container } \\
\text { Preparation: dried finger rhizomes are grounded to produce its powder }\end{array}$ & $\begin{array}{l}\text { Used as a spice, dye, medicine, } \\
\text { and as a dietary supplement }\end{array}$ \\
\hline Turmeric oil & $\begin{array}{l}\text { Appearance: yellow to brown oil } \\
\text { Chemical composition: essential oils from the leaves are usually dominated by } \\
\text { monoterpenes. Rhizomes oil mainly contains sesquiterpenes } \\
\text { Preparation: extract procured from dried rhizomes or leaves by steam distillation } \\
\text { or supercritical } \mathrm{CO}_{2} \text { extraction }\end{array}$ & $\begin{array}{l}\text { Used as spice, medicine, and } \\
\text { dietary supplement }\end{array}$ \\
\hline $\begin{array}{l}\text { Turmeric } \\
\text { oleoresins }\end{array}$ & $\begin{array}{c}\text { Appearance: dark yellow, reddish-brown viscous fluid } \\
\text { Chemical composition: they consist of up to } 25 \% \text { essential oil and } 37-55 \% \\
\text { curcuminoids } \\
\text { Preparation: extract from dried rhizomes by solvent extraction with organic } \\
\text { solvents (acetone, dichloromethane, 1,2-dichloroethane, methanol, ethanol, } \\
\text { isopropanol, and light petroleum (hexanes)) or by the application of supercritical } \\
\mathrm{CO}_{2} \text { extraction }\end{array}$ & $\begin{array}{l}\text { Used as a food coloring, } \\
\text { medicine, and dietary supplement }\end{array}$ \\
\hline Curcumin & $\begin{array}{l}\text { Appearance: crystalline powder of yellow to orange-red color } \\
\text { Chemical composition: a mixture of curcumin and its bisdemethoxy- and } \\
\text { demethoxy- derivatives (no fixed proportions). The three major curcuminoids } \\
\text { may occupy } 90 \% \text { of the whole proportion. Oils and resins may be the minority of } \\
\text { composition } \\
\text { Preparation: it is obtained by solvent extraction from ground turmeric rhizomes } \\
\text { followed by the purification of the extract through the crystallization process } \\
\text { Organic solvents used for extraction are acetone, carbon dioxide, ethanol, ethyl } \\
\text { acetate, hexane, methanol, and isopropanol }\end{array}$ & $\begin{array}{l}\text { Used as medicine and dietary } \\
\text { supplement }\end{array}$ \\
\hline
\end{tabular}

ionizing radiation (IR) indicates that curcumin application increases the sensitivity of lymphoma cells to IR-initiated apoptosis and improves G2/M phase arrest in the cell cycle [54]. Consequently, downregulation has been noted in the antiapoptotic $\mathrm{Bcl}-\mathrm{xL}$, cell cycle changing protein. Initiation of $\mathrm{G} 2 / \mathrm{M}$ phase arrest (by curcumin) was found connected with an obvious reduction in the cyclin A, cyclin B, and cyclin-dependent kinase 1 protein expression. Also, apoptosis induction by curcumin is escorted with upregulation of the Bax protein expression and downregulation of the Bcl2 protein amount which results in mitochondria dysfunction. Consequently, it leads to cytochrome $c$ release and sequential activation of caspase- 9 and caspase- 3 in the nasopharyngeal carcinoma-TW 076 cells. Therefore, it seems that mitochondria and apoptosis-inducing factor caspase-3dependent pathways are the fundamental figures in G2/M phase arrest and cell apoptosis by curcumin [55]. Curcumin also appreciably reduced the nuclear translocation of p65 and cytoplasmic $\mathrm{I} \kappa \mathrm{B} \alpha$ dilapidation. Survivin and hexokinase II have a trend to decrease by the curcumin pretreatment. Combined treatment of curcumin and L-asparaginase (LASP) initiates the apoptosis by activating various members of cysteine proteases (caspase- 8 and caspase-9/3) along with activating phase-I detoxification system. Curcumin acts synergistically with L-ASP in patients suffering from blood and bone marrow cancer [56-58]. Moreover, curcumin drastically decreases the castrate-resistant disease and human leiomyosarcoma cell lines propagation and interrupts the cell growth of uterine leiomyosarcoma by targeting the AKT-mammalian target of rapamycin pathway for reticence $[57,59]$.

Curcumin in appreciable amounts decreases the T cells, while a small amount of curcumin enhances the $\mathrm{T}$ cells extracted from mice carrying 3LL tumor. Hence, amplified CD8+ T cells showed improvement in IFN $-\gamma$ discharge and propagation particularly against 3LL tumor cells; all of these result in accomplishment of tumor inhibiting ability [60, 61].

The study regarding antiproliferative actions of turmeric components on human cancer cell lines including MDAMB-231, MCF-7, and HepG2 and immunomodulatory actions of turmerones on mononuclear cells of human blood indicated that the alpha-turmerone and curcuminoids appreciably suppress the production of cancer cells. Improvement in the propagation of peripheral blood mononuclear cells and the makeup of cytokine has been noted after the application of alpha-turmerone and aromatic-turmerone [62].

As mentioned in the introduction, curcumin possesses numerous pharmacological properties but its reduced solubility in water restricts its clinical use. Therefore, 
<smiles>COc1cc(/C=C/C(=O)CC(=O)/C=C/c2ccc(O)cc2)ccc1O</smiles>

(1)<smiles>O=C(/C=C/c1ccc(O)cc1)CC(=O)/C=C/c1ccc(O)cc1</smiles><smiles>COc1ccccc1OC1OC2(C(=O)[O-])OC1C(O)C2O</smiles>

(2)<smiles>COc1cc(/C=C/C(=O)CC(=O)/C=C/c2ccc(O)c(O)c2)ccc1O</smiles><smiles>C=C(O)/C=C/c1ccc(O[C@@H]2O[C@H](CO)[C@@H](O)[C@H](C)[C@H]2O)c(OC)c1</smiles>

(4)

(5)

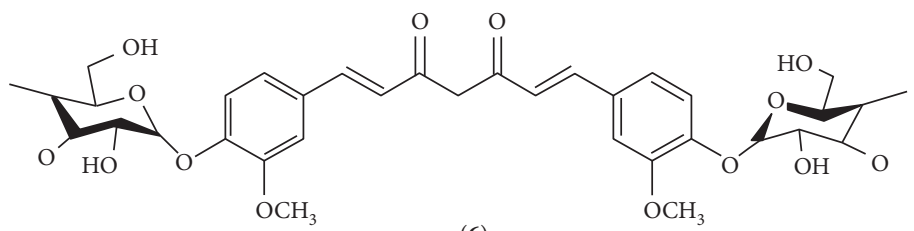<smiles>COc1cc(/C=C/C(=O)CC(=O)/C=C/c2ccc(O)c(OC)c2)ccc1O</smiles>

(6)<smiles>C=COc1ccc(/C=C/C(=O)CC(=O)/C=C/c2ccc(OC=C)c(OC)c2)cc1OC</smiles>

(8)

FIgURE 2: 2D molecular structures of curcumin: (1) demethoxycurcumin, (2) bisdemethoxycurcumin, (3) curcumin glucuronide, (4) monodemethylcurcumin, (5) curcumin monoglucoside, (6) curcumin diglucoside, (7) Keto-curcumin, and (8) allyl curcumin (obtained and modified from Open Chemistry Database, National Center for Biotechnology Information, and PubChem Substance Database; https:// pubchem.ncbi.nlm.nih.gov/substance).

preparation of curcumin into nanocarrier systems enhances its penetration into the tissues. For instance, curcuminloaded nanocapsules markedly decrease the tumor volume [63].

\section{Antioxidant and Anti-Inflammatory Activity}

Recently, especial attention has been paid to turmeric due to its antioxidant activities which are carried through direct 
scavenging of oxygen radicals and stimulating antioxidant responses by nuclear factor erythroid 2-related factor 2 (Nrf2) activation. That feature, besides the favorable outcomes on the endothelial function and the inflammatory state of the tissue and plasma, indicated that it was helpful for the treatment of diabetic microangiopathy potentially [63]. The bioactive components present in turmeric volatile oil include tumerone that is reported to be effective against carcinogenesis. The previous investigation indicated that turmeric had distinctive antioxidant potential [64]. Curcumin removed turmeric oleoresin which is the resource material for the production of curcumin and contains oil, resin, and nonextractable curcumin. During a lab study, various fractions and turmeric oil exhibited considerable antimutagenic and antioxidant ability [28]. Curcumin at a concentration of $200 \mathrm{mg} / \mathrm{kg}$ body weight of female Wistar rats appreciably reduced the oxidative damage in the hippocampus of rats when exposed to the organophosphate pesticides parathion; thus, it is an alternative to prevent neurodegenerative damage after pesticide exposure [65].

In addition, turmeric extract has been reported to possess strong antioxidant activity, as shown by ABTS and DPPH tests. The antioxidant ability of turmeric resulted in decreased levels of prostaglandin E2 (as a marker of oxidative stress) in HepG2 cells [66]. Curcumin is also helpful in increasing the lifespan of Caenorhabditis elegans by reducing the intracellular ROS and lipofuscin during aging [67].

Previous research conducted to examine the ability of turmeric to protect against lead-induced harm to the hippocampal cells of male Wistar rats demonstrated that it extensively prevented lipid peroxidation due to the exposure of toxic heavy metals. The reaction between curcumin and metals (cadmium and lead) resulted in formation of complex compounds that showed the effectiveness of curcumin in binding the metals [68].

It should be noted that curcumin alters the neuroendocrine role of the central nervous system, thus reducing chronic stress-induced disorders. Curcumin treatments mitigate the anxiety reaction because of its ability to prevent the neurons through the modification of nitric oxide making and brain-derived neurotrophic factor (BDNF) expression [69].

In fact, turmeric holds significant anti-inflammatory properties, mainly via Wnt/ $\beta$-catenin, nuclear factor-kappa $\mathrm{B}(\mathrm{NF}-\kappa \mathrm{B})$ (possibly by blockage of myeloid differentiation primary response 88 and toll-like receptor $4 / \mathrm{NF}-\kappa \mathrm{B}$ signal [70] and downregulating mRNA expression of NF- $\kappa$ B-p65 [71]), and mitogen-activated protein kinases pathways, and also by epigenetic modulatory role and redox regulation [72]. Another recent research showed the inhibitory effect of curcumin on NACHT, LRR, and PYD domain-containing protein 3 inflammasome activation [73]. Furthermore, it seems that signal transducer and activators of peroxisome proliferator-activated receptor- $\gamma(\operatorname{PPAR} \gamma)$ and transcription-3 are modulated by the turmeric supplementation [74]. A recent study explained its anti-inflammatory action through the phosphorylation repression of the I $\kappa \mathrm{B}$ kinase $\alpha$ and $\beta$ and $\mathrm{c}$-Jun $\mathrm{N}$-terminal kinase, too [75].

Some other scientists explained that obstruction in T-cellactivation-induced $\mathrm{Ca}^{2+}$ mobilization (IC50 $=\sim 12.5 \mu \mathrm{M}$ ) is another possible mechanism explaining anti-inflammatory and immunosuppressive ability of curcumin. They are also of the view that the same mechanism prevents nuclear factor of activated T-cell (NFAT) activation and NFAT-regulated cytokine expression. Moreover, curcumin can synergize with CsA to improve immunosuppressive action. In addition, because $\mathrm{Ca}^{2+}$ is also the vital messenger for the TCR-induced NF- $\kappa$ B signaling pathway, it provides another mechanism by which curcumin suppresses the NF- $\kappa \mathrm{B}$ activation [76]. A systematic review revealed that curcumin can make its anti-inflammatory effect by modifying several proinflammatory cytokines (e.g., TNF- $\alpha$, IL-6, and IL-8) in a physically active cohort [77]. The mentioned action was also observed in an in vitro model of intestinal inflammation. Besides it, the protective effect of turmeric on the intestinal epithelium may be promising for patients with inflammatory bowel disease [78]. Also, it has been shown that turmeric significantly lowers the level of high-sensitivity C-reactive protein (as an acute-phase protein) in a number of clinical trials $[79,80]$.

Furthermore, the role of curcumin in human ectopic endometriotic stromal cells secluded from women with endometriosis has been investigated. It was noted that the treatment of endometriotic stromal cells with curcumin indicated noticeable repression of mRNA expression of ICAM-1 and VCAM-1. Curcumin also drastically diminishes the TNF- $\alpha$-initiated cell surface and emergence of ICAM-1 and VCAM-1. Moreover, the application of curcumin on the endometriotic stromal cells clearly reduces the TNF- $\alpha$-initiated discharge of IL-6, IL-8, and monocyte chemoattractant protein-1 (MCP-1). Besides, curcumin subdues the commencement of transcription factor NF- $\kappa \mathrm{B}$ in human endometriotic stromal cells [40].

It has been studied that curcumin drastically reduces the pancreas injury and significantly improves the expression of PPAR $\gamma$. Curcumin application results in modulation of cytokine TNF- $\alpha$ release that could be a possible justification for its ability to attenuate the pancreas injury. These effects collectively lead to the upregulation of PPAR $\gamma$ and downregulation of NF- $\kappa \mathrm{B}[81,82]$. Spinal cord injury (SCI) including primary SCI and secondary SCI is due to inflammatory bursts. However, primary SCI is the consequence of direct injury to the spinal cord, but secondary injury results from subsequent edema and ischemia that lead to the activation of proinflammatory cytokines. These cytokines result in the activation of NF- $\kappa \mathrm{B}$ and create hindrance in spinal cord reinnervation because of gliosis. Turmeric can inhibit the $\mathrm{NF}-\kappa \mathrm{B}$, and epidural administration of curcumin results in increased recovery from SCI without any side effects. For that reason, curcumin treatment may decipher a new treatment for humans with SCI [83].

In the nutshell, conclusive scientific evidence is available, reporting the effectiveness of turmeric and its components/ 
fraction to treat the maladies characterized by oxidation and inflammation, thus warranting its use in dietary regimens.

\section{Antimicrobial Effects}

Turmeric may be an alternative antimicrobial agent against fatal bacterial infections [84]. The utilization of essential oil of turmeric leaves significantly inhibits fungal growth, as well as aflatoxins B1 and G1 production. Although curcumin is a very active agent, its reduced aqueous solubility hinders its applications. The nanocurcumin actually performs its antibacterial action by completely breaking the cell wall, leading to cell death [85].

Curcumin antibacterial activity against multidrug-resistant Acinetobacter baumannii noticeably increases in the presence of epigallocatechin gallate (EGCG). The combination of EGCG and curcumin can be used in medicine to avoid or control Acinetobacter baumannii infections [86].

Elimination of Acanthamoeba castellanii (as the causative agent for Acanthamoeba keratitis and granulomatous amoebic encephalitis) is complicated as the amoebas encyst makes it defiant to antiamoebic drugs. Amoebicidal activity of ethanol extracts of variant plants including peanut, sea daffodil, and turmeric was assessed on Acanthamoeba castellanii cysts. The results confirmed the inhibitory effect of the extracts on the duplication of Acanthamoeba cysts. However, the effect was time- and dose-dependent [87].

In addition, turmeric mouthwash can be successfully used as an adjunct method to mechanical plaque managing measures for the prevention of plaque and gingivitis. It should be noted that turmeric mouthwash results in significant diminution in total microbial count [88].

Turmeric hinders Bacillus subtilis and Escherichia coli growth by restraining filamenting temperature-sensitive mutant Z (FtsZ) (cytoskeletal protein) assembly through repressing the FtsZ polymerization [89]. Additionally, Khalafalla and his team estimated the anticoccidial activity of curcumin. They reported the sporozoites disconfiguration owing to inflammation and cell membrane corrugations [90]. Curcumin also dose-dependently reduces infectivity and cell proliferation. It dramatically represses the cytotoxicity of Vibrio vulnificus to HeLa cells by inhibiting $V$. vulnificus growth. Curcumin subdues both bacterial adhesion and RTX toxin binding to the host cells. Curcumin also inhibits the host cell rounding and actin aggregation. Moreover, curcumin reduces the $V$. vulnificus-induced NF$\kappa \mathrm{B}$ translocation in the HeLa cells [91].

It should be noted that curcumin, as the main ingredient of turmeric, has a wide-ranging antiviral activity [92]. For instance, there are several studies on its different mechanisms against human immunodeficiency viruses (HIVs). Curcumin has been shown to inhibit HIV-1 integrase [93]. Moreover, this polyphenol and its analogues can inhibit the infection and replication of viral genes. HIV protease and HIV associated kinases (e.g., tyrosine kinase) are inhibited by them. Also, curcumin has synergistic effect with biomedicine drugs [94].
It should be noted that curcumin inhibits the Apurinic/ apyrimidinic endonuclease- 1 redox function. Therefore, a wide variety of genes and pathways are affected. It has been found that curcumin can inhibit Kaposi's sarcoma-associated herpesvirus replication and then control the consequent pathologic processes (e.g., angiogenesis) [95].

There are a number of researches on anti-influenza activity of biological constituents of turmeric [96]. It can fight influenza-A virus (IAV) via the inhibition of its adsorption and replication [97]. Moreover, curcumin can balance the immune system response through product inhibition of local inflammatory cytokines in IAV infection. Furthermore, it has modulatory effect on NF- $\kappa$ B signaling in macrophages. In conclusion, it can play protective and ameliorative role in IAV-associated lung injury [98].

\section{Neuroprotective Effects}

Plant-derived components have been reported to not only provide neuroprotection but also manage biochemical pathways linked with symptoms of neurodegenerative disorders that comprise cognitive impairments, energy loss/ fatigue, mood changes, and anxiety. Furthermore, it has neurogenic potentials which seems to be done via the stimulation of neural stem cell proliferation and differentiation [99]. Plants and their products having neuroprotective effects might be a novel therapeutic approach to treat Parkinson's disease (PD) [100, 101]. Aggregation of $\alpha$-synuclein protein at high temperatures is a possible mechanism that leads to PD. Physiological pathway concerned in aggregation is unfolding the tetramer to kinetically trapped monomers that further arrange them, thus leading to the formation of fibrillar Lewy bodies. Therefore, avoiding reassociation of the monomers might be a helpful therapeutic approach to the prevention of $\mathrm{PD}$. In a few research studies, investigators reported the ability of turmeric's ingredient to bind to $\alpha$-synuclein, thus preventing the protein from aggregating and consequently escalating the rearrangement rate into a faster regime [102, 103]. However, most of the research studies highlighting neuroprotective possessions of turmeric in $\mathrm{PD}$ relied on rat models with different study durations. Some of their results showed that turmeric stimulates the enzyme action of $\gamma$-glutamyl cysteine ligase and guarded against protein nitration and disintegration of the neurons in the brain [104].

The onset of oxidative stress is another concern with mitochondrial degeneration leading to PD. Turmeric improves the glutathione (GSH) synthesis in experimental models, thus reducing the free radical damage and indeed oxidative stress. Bioconjugates of curcumin can play a major role against oxidative stress in dopaminergic neuronal cells and improve neuroprotection [105]. Curcumin improves the BDNF, phosphor-tyrosine kinase B (TrkB), phosphor-extracellular signal-regulated kinase, and AKT. It has been theorized that the neuroprotection of curcumin might be mediated via BDNF/TrkB-MAPK/PI-3K-CREB signaling pathway [106].

Alzheimer's disease (AD) also includes chronic inflammatory responses linked with both brain injury and 
beta-amyloid related pathology. It has been shown that oxidative stress and distressed protein metabolism and their interaction are central to $\mathrm{AD}$ pathogenesis [107]. Turmeric extract might be a potential source for the prevention of $\mathrm{AD}$ [108]. The brains of $\mathrm{AD}$ patients experience numerous modifications (i.e., distraction of protein synthesis, protein deprivation, and imbalanced heat shock response (HSR)). The HSR is responsible for the protection of the cells from a variety of stresses. Curcumin utilization could be a dietetic approach used to decrease oxidative injury and amyloid pathology connected with $\mathrm{AD}$; thus, it could be a powerful tool in the prevention of $\mathrm{AD}[107,109]$.

The encapsulation of bioactive components is gaining the attention of the researchers due to their claimed better efficacy. In a study, researchers evaluated the cytotoxicity of encapsulated nanoparticles of curcumin (Nps-Cur). They were of the view that human neuroblastoma SK-N-SH cells exposed to Nps-Cur showed the least signs of toxicity. Therefore, Nps-Cur can be a good option to provide neuroprotection to the patients suffering from $\mathrm{AD}$ [110].

Cerebral ischemia is related to the amplified TdT-mediated dUTP nick-end labeling (TUNEL) positive cells in brain sectors representing DNA disintegration. Treatment with curcuma oil may be helpful to reduce nitric oxide synthase (NOS) isoforms and noteworthy decline in the number of apoptotic cells during cerebral ischemia [111]. Also, curcumin reduces the expression of lipopolysaccharide-induced chemokine CCL2 mRNA and protein in C6 cells [112]. The water-soluble curcumin formulations $(50-200 \mathrm{mg} / \mathrm{kg})$ reduce the serenity period and enhance serotonin and dopamine levels in the brain tissues. As a result, these curcumin preparations might be a new opportunity for the modifications in the neurotransmitters and treatment of mental depression [113].

Finally, there are several studies on turmeric's neuroprotective effect in traumatic brain injury. Results showed this effect by decreased oxidative stress and cerebral edema, rise in BDNF level, protection of synaptic proteins and mitochondria, and microglial activation. Also, it has been shown that it can decrease in IL- 6 , TNF- $\alpha$, IL- $1 \beta$, and MCP1 and improve toll-like receptor 4 and aquaporin- 4 expression [114]. Additionally, the activation of the Nrf2 pathway is one of the most important mechanisms regarding this action [115].

8.1. Effects on Metabolic Syndrome, Related Disorders, and Cardiovascular Diseases. There are several recent systematic reviews on the effects of curcumin in patients with metabolic syndrome and related disorders. As the results of metaanalysis showed, there is a significant improvement regarding a wide variety of indices such as fasting blood sugar, insulin resistance index (i.e., HOMA-IR), glycated hemoglobin (i.e., HbAlc), triglycerides, leptin, adiponectin, total cholesterol, diastolic blood pressure, body mass index, and weight. However, it seems that its consumption is not associated with a significant change in systolic blood pressure and low-density lipoprotein cholesterol level, and hip ratio. It should be noted that there are discrepancies regarding its effect on high-density lipoprotein cholesterol and waist circumference [116-118].

In fact, the supplementation of turmeric extract exerts antiobesity effects by controlling the body weight, fat mass, serum lipids, and hepatic lipids. Furthermore, protein kinase A pathway-activated lipolysis might be another possible path [119]. The supplementation of lecithinized formulation of curcumin to diabetic patients (at a dose of $1 \mathrm{~g} /$ day) pointed out a decrease in the skin flux at the surface of the foot, improvement in microangiopathy, momentous reduction in the edema score, and a subsequent progress in the venoarteriolar reaction [120].

Furthermore, turmeric extract at the dose of $100-300 \mathrm{mg} / \mathrm{kg}$ of the body weight of hypercholesterolemic subjects showed considerable progress in vaso-relaxation. The levels of the antioxidant enzymes including superoxide dismutase and glutathione peroxides increased in subjects fed on diets containing turmeric extract, too [121].

The separation of curcuminoids also results in turmeric spent oleoresin (SOT) that is another fraction reported for some health benefits. SOT enriched with curcuminoids $(17.5 \%)$ can efficiently restrain angiotensin-converting enzyme and low-density lipoprotein oxidation. Likewise, curcuminoid-enriched fraction can lessen the risk of hypertension and cardiovascular diseases [122].

Different spices, including turmeric, have an inevitable role in the prevention and treatment of cardiovascular diseases. Modulating migratory, proliferative, and hypertrophic pathways, prohypertrophic signaling, and proliferation abilities of cardiac fibroblasts are some of the mechanistic aspects of its cardiovascular protection. In addition, it can make a balance between extracellular matrix components' synthesis and degradation [123-125].

There are so many preclinical researches on turmeric use for a wide variety of cardiovascular diseases such as myocardial infarction, heart failure, cardiac hypertrophy, atherosclerosis, stroke, abdominal aortic aneurysm, druginduced cardiotoxicity, and cardiomyopathy, and diabetes mellitus related cardiovascular problems. Also, there are a number of clinical trials about the efficacy of curcumin on cardiovascular risk factors [126-128].

Furthermore, turmeric and curcumin have well-known antidotal effects against natural and chemical agents-induced cardiovascular toxicity. Scientific reports suggested their beneficial roles in streptozotocin, methotrexate, doxorubicin, ciclosporin A, cadmium, isoproterenol, hydrogen peroxide, nicotine, diesel exhaust particle, tert-butyl hydroperoxide, and cyclophosphamide toxicities [129, 130].

\section{Safety and Toxicity}

Turmeric and its constituents were examined in many researches for their safety through in vitro studies, animal studies, and clinical trials. According to a comprehensive review on this subject, the administration of standardized powder/extract of turmeric and curcumin via oral route revealed no significant side effects or toxicities to animals. In addition, cell culture studies showed that "curcumin has antiproliferative effect in normal cells and can reduce cell 
viability." However, there were no reports about mutagenicity and genotoxicity. It seems that oral use of turmeric and curcumin in human is safe, even at extraordinary doses. Itching, tongue redness, tachycardia, and gastrointestinal complaints (e.g., flatulence, diarrhea, nausea, and constipation) were reported in a small proportion of cases. It should be noted that there are several problems regarding bioavailability of oral curcumin. However, its intravenous formulations have a greater absorption. Therefore, intravenous curcumin should be administered at lower doses than oral use [131].

It should be noted that curcumin may cause some kinds of pharmacokinetic alteration of cardiovascular medications, antibiotics, antidepressant agents, chemotherapeutic drugs, anticoagulants, and antihistamines. Therefore, its concomitant use with some conventional drugs should be done cautiously [132].

Oral use of turmeric and curcumin should be considered safe during pregnancy, according to animal studies. However, there is a report stating that oral curcumin about $1000 \mathrm{mg} / \mathrm{kg}$ body weight can cause a slight reduction of weight gain in F2 generation chicks [131].

Regarding the application of drug delivery technologies for improving turmeric bioavailability, safety of these modern formulations should be discussed. For instance, using carriers or surfactants as a bioavailability improving strategy may cause products to be toxic [133]. Also, some of the inorganic metal nanoparticles (e.g., gold-curcumin nanoparticles) are highly toxic [84].

However, most of these novel products seem to be safe. Solid lipid curcumin particle formulation showed no adverse effects in patients with osteosarcoma and healthy peoples [134]. Poly(N-isopropylacrylamide) delivery system, as another novel system which transports curcuminoids to the brain nasally, showed no toxicity [135]. Dipeptide nanoparticles of curcumin are safe, too. Dipeptide is synthesized from amino acids $\alpha, \beta$-dehydro phenylalanine and methionine, which are safe and capable of being decomposed in nature [136]. New curcumin analogues are another recently used option in medicine. According to in vivo studies, they showed no toxicities [137]. Moreover, nanoparticles of curcumin-loaded human serum albumin showed no toxicity during intravenous use in tumor xenograft HCT116 models [138]. In some cases, modernized formulation of curcumin seems to be safer than conventional ones. Results of a study on a novel intravenously injectable curcumin revealed that rabbits in curcumin nanosuspension group developed local irritation and phlebitis risks and erythrocyte hemolysis lesser than those in curcumin solution group [139].

\section{Conclusion}

The most widely used part of turmeric is its root, comprising loads of phytochemicals, vitamins, and minerals, quite beneficial for the cure of various human diseases. It seems that turmeric is a generally safe medicinal herb. However, its use during pregnancy and lactation and in patients with hepatic and renal failure should be assessed critically. Many products are extracted from turmeric. Its most active component, curcumin, followed by other significant components including curcuminoids atlantone, dimethoxycurcumin, diarylheptanoids, tumerone, and flavonoid curcumin (diferuloylmethane) has antimicrobial, anti-inflammatory, and antioxidant properties that provide its protective effect against different types of cellular injury. Moreover, turmeric and its constituents not only provide neuroprotection but also modulate the pathology of neurologic diseases like Parkinson's and Alzheimer's diseases. It has also been well documented to be an effective tool against various kinds of cancers. Furthermore, there are several researches on its effects against metabolic syndrome. To sum up, it could be concluded that turmeric and its components are recommended in dietary regimens to combat a wide variety of diseases. Further researches are necessitated for better understanding and judgment on its uses in clinical practice. Furthermore, regarding its constituents' bioavailability and drug delivery systems, developing modern formulations (e.g., nanoparticles, liposomes, and microspheres) and assessing their efficacy are suggested.

\section{Abbreviations}

\section{Longa: Curcuma longa}

TNF- $\alpha$ : Tumor necrosis factor alpha

ABTS: $\quad$ 2,2'-Azino-bis (3-ethylbenzothiazoline-6sulfonic acid)

AD: $\quad$ Alzheimer's disease

BDNF: Brain-derived neurotrophic factor

CDC27: Cell division cycle 27

COX-2: Cyclooxygenase 2

CRC: Colorectal cancer

NF- $\kappa$ B: Nuclear factor-kappa B

DPPH: 2,2-Diphenyl-1-picrylhydrazyl

EGCG: Epigallocatechin gallate

GSH: Glutathione

HSR: Heat shock response

ICAM-1: Intercellular Adhesion Molecule 1

IGF-1: Insulin-like growth factor-1

L-ASP: L-Asparaginase

MCP-1: Monocyte chemoattractant protein 1

NFAT: Nuclear factor of activated T cells

NF- $\kappa$ B: Nuclear factor-kappa B

NOS: $\quad$ Nitric oxide synthase

Nps-Cur: Encapsulated nanoparticles of curcumin

Nrf2: $\quad$ Nuclear factor erythroid 2-related factor 2

PD: $\quad$ Parkinson's disease

PPAR $\gamma$ : Peroxisome proliferator-activated receptor- $\gamma$

RANKL: Receptor activator of nuclear factor-kappa B ligand

ROS: $\quad$ Reactive oxygen species

SCI: $\quad$ Spinal cord injury

SOT: $\quad$ Turmeric spent oleoresin

TrkB: $\quad$ Tyrosine kinase B

TUNEL: TdT-mediated dUTP nick-end labeling

VCAM-1: Vascular cell adhesion molecule 1

STAT3: $\quad$ Signal transducer and activator of transcription 3

IR: Ionizing radiation

IL: Interleukin 
FtsZ: $\quad$ Filamenting temperature-sensitive mutant $\mathrm{Z}$

HIV: Human immunodeficiency viruses

IAV: Influenza-A virus.

\section{Conflicts of Interest}

The authors have no conflicts of interest to declare.

\section{Acknowledgments}

The authors thank the Library Department, Government College University Faisalabad (GCUF), and IT Department, Higher Education Commission (HEC), for the access to journals, books, and valuable database. Also, the authors would like to thank Professor N. Shokrpour for English editing of the manuscript.

\section{References}

[1] M. Hajimonfarednejad, M. Ostovar, M. J. Raee, M. H. Hashempur, J. G. Mayer, and M. Heydari, "Cinnamon: a systematic review of adverse events," Clinical Nutrition, vol. 38, no. 2, pp. 594-602, 2019.

[2] R. Zare, A. Nadjarzadeh, M. M. Zarshenas, M. Shams, and M. Heydari, "Efficacy of cinnamon in patients with type II diabetes mellitus: a randomized controlled clinical trial," Clinical Nutrition, vol. 38, no. 2, pp. 549-556, 2019.

[3] I. Siró, E. Kápolna, B. Kápolna, and A. Lugasi, "Functional food. Product development, marketing and consumer acceptance-A review," Appetite, vol. 51, no. 3, pp. 456-467, 2008.

[4] Z. Hajmohammadi, M. Heydari, M. Nimrouzi et al., "Rhus coriaria L. increases serum apolipoprotein-A1 and highdensity lipoprotein cholesterol levels: a double-blind placebo-controlled randomized clinical trial," Journal of Integrative Medicine, vol. 16, no. 1, pp. 45-50, 2018.

[5] A. Shakeri, M. H. Hashempur, M. Mojibian, F. Aliasl, S. Bioos, and F. Nejatbakhsh, "A comparative study of ranitidine and quince (Cydonia oblonga mill) sauce on gastroesophageal reflux disease (GERD) in pregnancy: a randomised, open-label, active-controlled clinical trial," Journal of Obstetrics and Gynaecology, vol. 38, no. 7, pp. 1-7, 2018.

[6] M. H. Hashempur, F. Khademi, M. Rahmanifard, and M. M. Zarshenas, "An evidence-based study on medicinal plants for hemorrhoids in Medieval Persia," Journal of Evidence-Based Complementary \& Alternative Medicine, vol. 22, no. 4, pp. 969-981, 2017.

[7] T. Tsuda, "Curcumin as a functional food-derived factor: degradation products, metabolites, bioactivity, and future perspectives," Food \& Function, vol. 9, no. 2, pp. 705-714, 2018.

[8] S. C. Gupta, B. Sung, J. H. Kim, S. Prasad, S. Li, and B. B. Aggarwal, "Multitargeting by turmeric, the golden spice: from kitchen to clinic," Molecular Nutrition \& Food Research, vol. 57, no. 9, pp. 1510-1528, 2013.

[9] K. P. Nair, The Agronomy and Economy of Turmeric and Ginger: The Invaluable Medicinal Spice Crops, Newnes, London, UK, 2013.

[10] F. Delgado-Vargas and O. Paredes-López, Natural Colorants for Food and Nutraceutical Uses, CRC Press, Boca Raton, FL, USA, 2002.
[11] G. A. F. Hendry and J. Houghton, Natural Food Colorants, Springer Science \& Business Media, Berlin, Germany, 1996.

[12] R. F. Tayyem, D. D. Heath, W. K. Al-Delaimy, and C. L. Rock, "Curcumin content of turmeric and curry powders," Nutrition and Cancer, vol. 55, no. 2, pp. 126-131, 2006.

[13] C. R. Ireson, D. J. Jones, S. Orr et al., "Metabolism of the cancer chemopreventive agent curcumin in human and rat intestine," Cancer Epidemiology and Prevention Biomarkers, vol. 11, no. 1, pp. 105-111, 2002.

[14] T.-T. Phan, P. See, S.-T. Lee, and S.-Y. Chan, "Protective effects of curcumin against oxidative damage on skin cells in vitro: its implication for wound healing," The Journal of Trauma: Injury, Infection, and Critical Care, vol. 51, no. 5, pp. 927-931, 2001.

[15] A. J. Ruby, G. Kuttan, K. Dinesh Babu, K. N. Rajasekharan, and R. Kuttan, "Anti-tumour and antioxidant activity of natural curcuminoids," Cancer Letters, vol. 94, no. 1, pp. 79-83, 1995.

[16] B. B. Aggarwal, A. Kumar, and A. C. Bharti, "Anticancer potential of curcumin: preclinical and clinical studies," Anticancer Research, vol. 23, no. 1/A, pp. 363-398, 2003.

[17] P. Gul and J. Bakht, "Antimicrobial activity of turmeric extract and its potential use in food industry," Journal of Food Science and Technology, vol. 52, no. 4, pp. 2272-2279, 2015.

[18] J. Miquel, A. Bernd, J. M. Sempere, J. Díaz-Alperi, and A. Ramírez, "The curcuma antioxidants: pharmacological effects and prospects for future clinical use. A review," Archives of Gerontology and Geriatrics, vol. 34, no. 1, pp. 37-46, 2002.

[19] N. M. K. Selvi, M. Sridhar, R. Swaminathan, and R. Sripradha, "Efficacy of turmeric as adjuvant therapy in type 2 diabetic patients," Indian Journal of Clinical Biochemistry, vol. 30, no. 2, pp. 180-186, 2015.

[20] R. Srimal, "Turmeric: a brief review of medicinal properties," Fitoterapia, vol. 68, pp. 483-493, 1997.

[21] D. Mehrabani, M. Farjam, B. Geramizadeh, N. Tanideh, M. Amini, and M. R. Panjehshahin, "The healing effect of curcumin on burn wounds in rat," World Journal of Plastic Surgery, vol. 4, no. 4, pp. 29-35, 2015.

[22] P. S. Babu and K. Srinivasan, "Hypolipidemic action of curcumin, the active principle of turmeric (Curcuma longa) in streptozotocin induced diabetic rats," Molecular and Cellular Biochemistry, vol. 166, no. 1-2, pp. 169-175, 1997.

[23] A. Duvoix, R. Blasius, S. Delhalle et al., "Chemopreventive and therapeutic effects of curcumin," Cancer Letters, vol. 223, no. 2, pp. 181-190, 2005.

[24] G. Garcea, D. P. Berry, D. J. Jones et al., "Consumption of the putative chemopreventive agent curcumin by cancer patients: assessment of curcumin levels in the colorectum and their pharmacodynamic consequences," Cancer Epidemiology and Prevention Biomarkers, vol. 14, no. 1, pp. 120-125, 2005.

[25] P. R. Holt, S. Katz, and R. Kirshoff, "Curcumin therapy in inflammatory bowel disease: a pilot study," Digestive Diseases and Sciences, vol. 50, no. 11, pp. 2191-2193, 2005.

[26] M. Iqbal, S. D. Sharma, Y. Okazaki, M. Fujisawa, and S. Okada, "Dietary supplementation of curcumin enhances antioxidant and phase II metabolizing enzymes in ddY male mice: possible role in protection against chemical carcinogenesis and toxicity," Pharmacology and Toxicology, vol. 92, no. 1, pp. 33-38, 2003. 
[27] R. A. Sharma, A. J. Gescher, and W. P. Steward, "Curcumin: the story so far," European Journal of Cancer, vol. 41, no. 13, pp. 1955-1968, 2005.

[28] G. K. Jayaprakasha, B. S. Jena, P. S. Negi, and K. K. Sakariah, "Evaluation of antioxidant activities and antimutagenicity of turmeric oil: a byproduct from curcumin production," Zeitschrift für Naturforschung C, vol. 57, no. 9-10, pp. 828835, 2002.

[29] A. Y. Leung, Encyclopedia of Common Natural Ingredients Used in Food, Drugs, and Cosmetics, Wiley, Hoboken, NJ, USA, 1980.

[30] K. U. Pradeep, P. Geervani, and B. O. Eggum, "Common Indian spices: nutrient composition, consumption and contribution to dietary value," Plant Foods for Human Nutrition, vol. 44, no. 2, pp. 137-148, 1993.

[31] S. Li, W. Yuan, G. Deng, P. Wang, P. Yang, and B. B. Aggarwal, "Chemical composition and product quality control of turmeric (Curcuma longa L.)," Pharmaceutical Crops, vol. 2, no. 1, 2011.

[32] S. Singh, "From exotic spice to modern drug?" Cell, vol. 130, no. 5, pp. 765-768, 2007.

[33] M. Farjam, D. Mehrabani, F. Abbassnia et al., "The healing effect of Curcuma longa on liver in experimental acute hepatic encephalopathy of rat," Comparative Clinical $\mathrm{Pa}$ thology, vol. 23, no. 6, pp. 1669-1673, 2014.

[34] Y. Zhu and S. Bu, "Curcumin induces autophagy, apoptosis, and cell cycle arrest in human pancreatic cancer cells," Evidence-Based Complementary and Alternative Medicine, vol. 2017, 2017.

[35] X. Song, M. Zhang, E. Dai, and Y. Luo, "Molecular targets of curcumin in breast cancer," Molecular Medicine Reports, vol. 19, no. 1, pp. 23-29, 2019.

[36] P. D. Kasi, R. Tamilselvam, K. Skalicka-Woźniak et al., "Molecular targets of curcumin for cancer therapy: an updated review," Tumor Biology, vol. 37, no. 10, pp. 13017-13028, 2016.

[37] H. Mirzaei, A. Masoudifar, A. Sahebkar et al., "MicroRNA: a novel target of curcumin in cancer therapy," Journal of Cellular Physiology, vol. 233, no. 4, pp. 3004-3015, 2018.

[38] S. S. Soflaei, A. A. Momtazi-Borojeni, M. Majeed, G. Derosa, P. Maffioli, and A. Sahebkar, "Curcumin: a natural panHDAC inhibitor in cancer," Current Pharmaceutical Design, vol. 24, no. 2, pp. 123-129, 2018.

[39] M. J. Gunter and M. F. Leitzmann, "Obesity and colorectal cancer: epidemiology, mechanisms and candidate genes," The Journal of Nutritional Biochemistry, vol. 17, no. 3, pp. 145-156, 2006.

[40] X.-F. Huang and J.-Z. Chen, "Obesity, the PI3K/Akt signal pathway and colon cancer," Obesity Reviews, vol. 10, no. 6, pp. 610-616, 2009.

[41] P. Szlosarek, K. A. Charles, and F. R. Balkwill, "Tumour necrosis factor- $\alpha$ as a tumour promoter," European Journal of Cancer, vol. 42, no. 6, pp. 745-750, 2006.

[42] S. Chuengsamarn, S. Rattanamongkolgul, R. Luechapudiporn, C. Phisalaphong, and S. Jirawatnotai, "Curcumin extract for prevention of type 2 diabetes," Diabetes Care, vol. 35, no. 11, pp. 2121-2127, 2012.

[43] M.-J. Chen, Y.-M. Cheng, P.-H. Lai, J.-F. Wu, and Y.-C. Hsu, "In vitro biocompatibility of thermally gelling liquid mucoadhesive loaded curcuminoids in colorectal cancer chemoprevention," International Journal of Colorectal Disease, vol. 27, no. 7, pp. 869-878, 2012.
[44] K. Troselj and R. Kujundzic, "Curcumin in combined cancer therapy," Current Pharmaceutical Design, vol. 20, no. 42, pp. 6682-6696, 2014.

[45] L. Jiménez-Flores, S. López-Briones, M. Macías-Cervantes, J. Ramírez-Emiliano, and V. Pérez-Vázquez, “A PPAR $\gamma$, NF$\kappa \mathrm{B}$ and AMPK-dependent mechanism may be involved in the beneficial effects of curcumin in the diabetic $\mathrm{db} / \mathrm{db}$ mice liver," Molecules, vol. 19, no. 6, pp. 8289-8302, 2014.

[46] J. H. Kim, S. C. Gupta, B. Park, V. R. Yadav, and B. B. Aggarwal, "Turmeric (Curcuma longa) inhibits inflammatory nuclear factor (NF)- $\kappa \mathrm{B}$ and NF- $\kappa \mathrm{B}$-regulated gene products and induces death receptors leading to suppressed proliferation, induced chemosensitization, and suppressed osteoclastogenesis," Molecular Nutrition \& Food Research, vol. 56, no. 3, pp. 454-465, 2012.

[47] G. Lee, J.-Y. Joung, J.-H. Cho, C.-G. Son, and N. Lee, "Overcoming P-Glycoprotein-Mediated multidrug resistance in colorectal cancer: potential reversal agents among herbal medicines," Evidence-Based Complementary and Alternative Medicine, vol. 2018, Article ID 3412074, 9 pages, 2018.

[48] S. Kössler, C. Nofziger, M. Jakab, S. Dossena, and M. Paulmichl, "Curcumin affects cell survival and cell volume regulation in human renal and intestinal cells," Toxicology, vol. 292, no. 2-3, pp. 123-135, 2012.

[49] J. Yu, X. Zhou, X. He, M. Dai, and Q. Zhang, "Curcumin induces apoptosis involving bax/bcl-2 in human hepatoma SMMC-7721 cells," Asian Pac J Cancer Prev, vol. 12, no. 8, pp. 1925-1929, 2011.

[50] S. J. Lee and S. A. Langhans, “Anaphase-promoting complex/ cyclosome protein Cdc27 is a target for curcumin-induced cell cycle arrest and apoptosis," BMC Cancer, vol. 12, no. 1, p. 44, 2012.

[51] D. Ma, P. Tremblay, K. Mahngar, J. Collins, T. Hudlicky, and S. Pandey, "Selective cytotoxicity against human osteosarcoma cells by a novel synthetic C-1 analogue of 7-deoxypancratistatin is potentiated by curcumin," PLoS One, vol. 6, no. 12, Article ID e28780, 2011.

[52] K. L. Nair, A. K. T. Thulasidasan, G. Deepa, R. J. Anto, and G. V. Kumar, "Purely aqueous PLGA nanoparticulate formulations of curcumin exhibit enhanced anticancer activity with dependence on the combination of the carrier," International Journal of Pharmaceutics, vol. 425, no. 1-2, pp. 44-52, 2012.

[53] H. Yin, R. Guo, Y. Xu et al., "Synergistic antitumor efficiency of docetaxel and curcumin against lung cancer," Acta Biochimica et Biophysica Sinica, vol. 44, no. 2, pp. 147-153, 2011.

[54] Q. Qiao, Y. Jiang, and G. Li, "Curcumin improves the antitumor effect of X-ray irradiation by blocking the NF- $\kappa \mathrm{B}$ pathway," Anti-cancer Drugs, vol. 23, no. 6, pp. 597-605, 2012.

[55] C. L. Kuo, S. Y. Wu, S. W Ip et al., "Apoptotic death in curcumin-treated NPC-TW 076 human nasopharyngeal carcinoma cells is mediated through the ROS, mitochondrial depolarization and caspase-3-dependent signaling responses," International Journal of Oncology, vol. 39, no. 39, pp. 319-328, 2011.

[56] A.-J. Jiang, G. Jiang, L.-T. Li, and J.-N. Zheng, "Curcumin induces apoptosis through mitochondrial pathway and caspases activation in human melanoma cells," Molecular Biology Reports, vol. 42, no. 1, pp. 267-275, 2015.

[57] S. A. Shah, S. Prasad, and K. E. Knudsen, "Targeting pioneering factor and hormone receptor cooperative pathways 
to suppress tumor progression," Cancer Research, vol. 72, no. 5, pp. 1248-1259, 2012.

[58] H. Wang, Q.-R. Geng, L. Wang, and Y. Lu, "Curcumin potentiates antitumor activity ofl-asparaginase via inhibition of the AKT signaling pathway in acute lymphoblastic leukemia," Leukemia \& Lymphoma, vol. 53, no. 7, pp. 1376-1382, 2012.

[59] T. F. Wong, T. Takeda, B. Li et al., "Curcumin disrupts uterine leiomyosarcoma cells through AKT-mTOR pathway inhibition," Gynecologic Oncology, vol. 122, no. 1, pp. 141-148, 2011.

[60] F. Han, B. Luo, R. Shi et al., "Curcumin ameliorates rat experimental autoimmune neuritis," Journal of Neuroscience Research, vol. 92, no. 6, pp. 743-750, 2014.

[61] F. Luo, X. Song, Y. Zhang, and Y. Chu, "Low-dose curcumin leads to the inhibition of tumor growth via enhancing CTLmediated antitumor immunity," International Immunopharmacology, vol. 11, no. 9, pp. 1234-1240, 2011.

[62] G. G. Yue, B. C. Chan, P.-M. Hon et al., "Evaluation of in vitro anti-proliferative and immunomodulatory activities of compounds isolated from Curcuma longa," Food and Chemical Toxicology, vol. 48, no. 8-9, pp. 2011-2020, 2010.

[63] L. Mazzarino, L. F. C. Silva, J. C. Curta et al., "Curcuminloaded lipid and polymeric nanocapsules stabilized by nonionic surfactants: an in vitro and in vivo antitumor activity on B16-F10 melanoma and macrophage uptake comparative study," Journal of Biomedical Nanotechnology, vol. 7, no. 3, pp. 406-414, 2011.

[64] E. Chinedum, E. Kate, C. Sonia, A. Ironkwe, and I. Andrew, "Polyphenolic composition and antioxidant activities of 6 new turmeric (Curcuma longa L.) accessions," Recent Patents on Food, Nutrition \& Agriculture, vol. 7, no. 1, pp. 22-27, 2015.

[65] A. A. Canales-Aguirre, U. A. Gomez-Pinedo, S. Luquin, M. A. Ramírez-Herrera, M. L. Mendoza-Magaña, and A. Feria-Velasco, "Curcumin protects against the oxidative damage induced by the pesticide parathion in the hippocampus of the rat brain," Nutritional Neuroscience, vol. 15, no. 2, pp. 62-69, 2012.

[66] L. Menghini, S. Genovese, F. Epifano, B. Tirillini, C. Ferrante, and L. Leporini, "Antiproliferative, protective and antioxidant effects of artichoke, dandelion, turmeric and rosemary extracts and their formulation," International Journal of Immunopathology and Pharmacology, vol. 23, no. 2, pp. 601-610, 2010.

[67] V. H.-C. Liao, C.-W. Yu, Y.-J. Chu, W.-H. Li, Y.-C. Hsieh, and T.-T. Wang, "Curcumin-mediated lifespan extension in Caenorhabditis elegans," Mechanisms of Ageing and Development, vol. 132, no. 10, pp. 480-487, 2011.

[68] S. Daniel, J. L. Limson, A. Dairam, G. M. Watkins, and S. Daya, "Through metal binding, curcumin protects against lead- and cadmium-induced lipid peroxidation in rat brain homogenates and against lead-induced tissue damage in rat brain," Journal of Inorganic Biochemistry, vol. 98, no. 2, pp. 266-275, 2004.

[69] S. Wei, H. Xu, D. Xia, and R. Zhao, "Curcumin attenuates the effects of transport stress on serum cortisol concentration, hippocampal NO production, and BDNF expression in the pig," Domestic Animal Endocrinology, vol. 39, no. 4, pp. 231-239, 2010.

[70] Y. Zhang and Y. Zeng, "Curcumin reduces inflammation in knee osteoarthritis rats through blocking TLR4/MyD88/NF$\kappa \mathrm{B}$ signal pathway," Drug Development Research, vol. 80, no. 3, pp. 353-359, 2019.
[71] S. Suresh, P. Sankar, A. G. Telang, M. Kesavan, and S. N. Sarkar, "Nanocurcumin ameliorates Staphylococcus aureus-induced mastitis in mouse by suppressing NF- $\kappa \mathrm{B}$ signaling and inflammation," International Immunopharmacology, vol. 65, pp. 408-412, 2018.

[72] C. Li, X. Miao, F. Li et al., "Curcuminoids: implication for inflammation and oxidative stress in cardiovascular diseases," Phytotherapy Research, vol. 33, no. 5, pp. 1302-1317, 2019.

[73] H. Yin, Q. Guo, X. Li et al., "Curcumin suppresses IL-1 $\beta$ secretion and prevents inflammation through inhibition of the NLRP3 inflammasome," The Journal of Immunology, vol. 200, no. 8, pp. 2835-2846, 2018.

[74] R. Tabrizi, S. Vakili, M. Akbari et al., "The effects of curcumin-containing supplements on biomarkers of inflammation and oxidative stress: a systematic review and metaanalysis of randomized controlled trials," Phytotherapy Research, vol. 33, no. 2, pp. 253-262, 2019.

[75] A. Sadeghi, A. Rostamirad, S. Seyyedebrahimi, and R. Meshkani, "Curcumin ameliorates palmitate-induced inflammation in skeletal muscle cells by regulating JNK/NF$\mathrm{kB}$ pathway and ROS production," Inflammopharmacology, vol. 26, no. 5, pp. 1265-1272, 2018.

[76] C. Kliem, A. Merling, M. Giaisi, R. Köhler, P. H. Krammer, and M. Li-Weber, "Curcumin suppresses T cell activation by blocking Ca 2+ mobilization and nuclear factor of activated T cells (NFAT) activation," Journal of Biological Chemistry, vol. 287, no. 13, pp. 10200-10209, 2012.

[77] D. Fernández-Lázaro, J. Mielgo-Ayuso, J. Seco Calvo, A. Córdova Martínez, A. Caballero García, and C. I. Fernandez-Lazaro, "Modulation of exercise-induced muscle damage, inflammation, and oxidative markers by curcumin supplementation in a physically active population: a systematic review," Nutrients, vol. 12, no. 2, p. 501, 2020.

[78] P. Governa, M. Marchi, V. Cocetta et al., "Effects of Boswellia Serrata Roxb. and Curcuma longa L. in an in vitro intestinal inflammation model using immune cells and Caco-2," Pharmaceuticals, vol. 11, no. 4, p. 126, 2018.

[79] S. Saraf-Bank, A. Ahmadi, Z. Paknahad, M. Maracy, and M. Nourian, "Effects of curcumin supplementation on markers of inflammation and oxidative stress among healthy overweight and obese girl adolescents: a randomized placebo-controlled clinical trial," Phytotherapy Research, vol. 33, no. 8, pp. 2015-2022, 2019.

[80] F. Samadian, N. Dalili, F. Poor -reza Gholi et al., "Evaluation of Curcumin's effect on inflammation in hemodialysis patients," Clinical Nutrition ESPEN, vol. 22, pp. 19-23, 2017.

[81] W. G. Yu, G. Xu, G. J Ren et al., "Preventive action of curcumin in experimental acute pancreatitis in mouse," The Indian Journal of Medical Research, vol. 134, no. 134, pp. 717-24, 2011.

[82] Z.-J. Liu, H.-Q. Liu, C. Xiao et al., "Curcumin protects neurons against oxygen-glucose deprivation/reoxygenationinduced injury through activation of peroxisome proliferator-activated receptor- $\gamma$ function," Journal of Neuroscience Research, vol. 92, no. 11, pp. 1549-1559, 2014.

[83] D. R. Ormond, H. Peng, R. Zeman, K. Das, R. Murali, and M. Jhanwar-Uniyal, "Recovery from spinal cord injury using naturally occurring antiinflammatory compound curcumin," Journal of Neurosurgery: Spine, vol. 16, no. 5, pp. 497-503, 2012.

[84] K. Sindhu, R. Indra, A. Rajaram, K. J. Sreeram, and R. Rajaram, "Investigations on the interaction of gold-curcumin nanoparticles with human peripheral 
blood lymphocytes," Journal of Biomedical Nanotechnology, vol. 7, no. 1, p. 56, 2011.

[85] R. K. Basniwal, H. S. Buttar, V. Jain, and N. Jain, "Curcumin nanoparticles: preparation, characterization, and antimicrobial study," Journal of Agricultural and Food Chemistry, vol. 59, no. 5, pp. 2056-2061, 2011.

[86] J. W. Betts and D. W. Wareham, "In vitro activity of curcumin in combination with epigallocatechin gallate (EGCG) versus multidrug-resistant Acinetobacter baumannii," BMC Microbiology, vol. 14, no. 1, p. 172, 2014.

[87] N. M. El-Sayed, K. A. Ismail, S. A.-E.-G. Ahmed, and M. H. Hetta, "In vitro amoebicidal activity of ethanol extracts of Arachis hypogaea L., Curcuma longa L. and Pancratium maritimum L. on Acanthamoeba castellanii cysts," Parasitology Research, vol. 110, no. 5, pp. 1985-1992, 2012.

[88] P. Waghmare, A. Chaudhari, V. Karhadkar, and A. Jamkhande, "Comparative evaluation of turmeric and chlorhexidinegluconate mouthwash in prevention of plaque formationand gingivitis: a clinical and microbiological study," The Journal of Contemporary Dental Practice, vol. 12, no. 4, pp. 221-224, 2011.

[89] C. D. Kaur and S. Saraf, "Topical vesicular formulations of Curcuma longa extract on recuperating the ultraviolet radiation-damaged skin," Journal of Cosmetic Dermatology, vol. 10, no. 4, pp. 260-265, 2011.

[90] R. E. Khalafalla, U. Müller, M. Shahiduzzaman et al., "Effects of curcumin (diferuloylmethane) on Eimeria tenella sporozoites in vitro," Parasitology Research, vol. 108, no. 4, pp. 879-886, 2011.

[91] H. S. Na, M. H. Cha, D.-R. Oh, C.-W. Cho, J. H. Rhee, and Y. R. Kim, "Protective mechanism of curcumin againstVibrio vulnificusinfection," FEMS Immunology \& Medical Microbiology, vol. 63, no. 3, pp. 355-362, 2011.

[92] S. Zorofchian Moghadamtousi, H. Abdul Kadir, P. Hassandarvish, H. Tajik, S. Abubakar, and K. Zandi, "A review on antibacterial, antiviral, and antifungal activity of curcumin," BioMed Research International, vol. 2014, 2014.

[93] E. De Clercq, "Current lead natural products for the chemotherapy of human immunodeficiency virus (HIV) infection," Medicinal Research Reviews, vol. 20, no. 5, pp. 323-349, 2000.

[94] S. Prasad and A. K. Tyagi, "Curcumin and its analogues: a potential natural compound against HIV infection and AIDS," Food \& Function, vol. 6, no. 11, pp. 3412-3419, 2015.

[95] H. Li, C. Zhong, Q. Wang, W. Chen, and Y. Yuan, "Curcumin is an APE1 redox inhibitor and exhibits an antiviral activity against KSHV replication and pathogenesis," Antiviral Research, vol. 167, pp. 98-103, 2019.

[96] S. M. Richart, Y.-L. Li, Y. Mizushina et al., "Synergic effect of curcumin and its structural analogue (Monoacetylcurcumin) on anti-influenza virus infection," Journal of Food and Drug Analysis, vol. 26, no. 3, pp. 1015-1023, 2018.

[97] J. Dai, L. Gu, Y. Su et al., "Inhibition of curcumin on influenza A virus infection and influenzal pneumonia via oxidative stress, TLR2/4, p38/JNK MAPK and NF- $\kappa \mathrm{B}$ pathways," International Immunopharmacology, vol. 54, pp. 177-187, 2018.

[98] S. Han, J. Xu, X. Guo, and M. Huang, "Curcumin ameliorates severe influenza pneumonia via attenuating lung injury and regulating macrophage cytokines production," Clinical and Experimental Pharmacology and Physiology, vol. 45, no. 1, pp. 84-93, 2018.

[99] S. Heidari, S. Mahdiani, M. Hashemi, and F. Kalalinia, "Recent advances in neurogenic and neuroprotective effects of curcumin through the induction of neural stem cells," Biotechnology and Applied Biochemistry, 2020.

[100] R. Kannappan, S. C. Gupta, J. H. Kim, S. Reuter, and B. B. Aggarwal, "Neuroprotection by spice-derived nutraceuticals: you are what you eat!" Molecular Neurobiology, vol. 44, no. 2, pp. 142-159, 2011.

[101] R. B. Mythri and M. M. Srinivas Bharath, "Curcumin: a potential neuroprotective agent in Parkinson's disease," Current Pharmaceutical Design, vol. 18, no. 1, pp. 91-99, 2012.

[102] B. Ahmad and L. J. Lapidus, "Curcumin prevents aggregation in $\alpha$-synuclein by increasing reconfiguration rate," Journal of Biological Chemistry, vol. 287, no. 12, pp. 9193-9199, 2012.

[103] H.-F. Ji and L. Shen, "The multiple pharmaceutical potential of curcumin in Parkinson's disease," CNS \& Neurological Disorders-Drug Targets, vol. 13, no. 2, pp. 369-373, 2014.

[104] R. B. Mythri, J. Veena, G. Harish, B. S. Shankaranarayana Rao, and M. M. Srinivas Bharath, "Chronic dietary supplementation with turmeric protects against 1-methyl-4phenyl-1,2,3,6-tetrahydropyridine-mediated neurotoxicity in vivo: implications for Parkinson's disease," British Journal of Nutrition, vol. 106, no. 1, pp. 63-72, 2011.

[105] G. Harish, C. Venkateshappa, R. B. Mythri et al., "Bioconjugates of curcumin display improved protection against glutathione depletion mediated oxidative stress in a dopaminergic neuronal cell line: implications for Parkinson's disease," Bioorganic \& Medicinal Chemistry, vol. 18, no. 7, pp. 2631-2638, 2010.

[106] R. Wang, Y.-H. Li, Y. Xu et al., "Curcumin produces neuroprotective effects via activating brain-derived neurotrophic factor/TrkB-dependent MAPK and PI-3K cascades in rodent cortical neurons," Progress in Neuro-Psychopharmacology and Biological Psychiatry, vol. 34, no. 1, pp. 147-153, 2010.

[107] V. Calabrese, D. A. Butterfield, and A. M. Stella, "Nutritional antioxidants and the heme oxygenase pathway of stress tolerance: novel targets for neuroprotection in Alzheimer's disease," The Italian Journal of Biochemistry, vol. 52, no. 52, pp. 177-181, 2003.

[108] M. Divino da Rocha, F. Pereira Dias Viegas, H. Cristina Campos et al., "The role of natural products in the discovery of new drug candidates for the treatment of neurodegenerative disorders II: alzheimers disease," CNS \& Neurological Disorders - Drug Targets, vol. 10, no. 2, pp. 251-270, 2011.

[109] D. Yanagisawa, N. F. Ibrahim, H. Taguchi et al., "Curcumin derivative with the substitution at C-4 position, but not curcumin, is effective against amyloid pathology in APP/PS1 mice," Neurobiology of Aging, vol. 36, no. 1, pp. 201-210, 2015.

[110] S. Doggui, J. K. Sahni, M. Arseneault, L. Dao, and C. Ramassamy, "Neuronal uptake and neuroprotective effect of curcumin-loaded PLGA nanoparticles on the human SKN-SH cell line," Journal of Alzheimer's Disease, vol. 30, no. 2, pp. 377-392, 2012.

[111] P. Dohare, S. Varma, and M. Ray, "Curcuma oil modulates the nitric oxide system response to cerebral ischemia/ reperfusion injury," Nitric Oxide, vol. 19, no. 1, pp. 1-11, 2008.

[112] Z.-J. Zhang, L.-X. Zhao, D.-L. Cao, X. Zhang, Y.-J. Gao, and C. Xia, "Curcumin inhibits LPS-induced CCL2 expression via JNK pathway in C6 rat astrocytoma cells," Cellular and Molecular Neurobiology, vol. 32, no. 6, pp. 1003-1010, 2012.

[113] S. Kulkarni, K. K. Akula, and J. Deshpande, "Evaluation of antidepressant-like activity of novel water-soluble curcumin 
formulations and St. John's wort in behavioral paradigms of despair," Pharmacology, vol. 89, no. 1-2, pp. 83-90, 2012.

[114] Z. Keshavarzi, F. Shakeri, G. E. Barreto, B. Bibak, T. Sathyapalan, and A. Sahebkar, "Medicinal plants in traumatic brain injury: neuroprotective mechanisms revisited," BioFactors, vol. 45, no. 4, pp. 517-535, 2019.

[115] W. Dong, B. Yang, L. Wang et al., "Curcumin plays neuroprotective roles against traumatic brain injury partly via Nrf2 signaling," Toxicology and Applied Pharmacology, vol. 346, pp. 28-36, 2018.

[116] M. Akbari, K. B. Lankarani, R. Tabrizi et al., "The effects of curcumin on weight loss among patients with metabolic syndrome and related disorders: a systematic review and meta-analysis of randomized controlled trials," Frontiers in Pharmacology, vol. 10, 2019.

[117] M. Azhdari, M. Karandish, and A. Mansoori, "Metabolic benefits of curcumin supplementation in patients with metabolic syndrome: a systematic review and meta-analysis of randomized controlled trials," Phytotherapy Research, vol. 33, no. 5, pp. 1289-1301, 2019.

[118] R. Tabrizi, S. Vakili, K. B. Lankarani et al., "The effects of curcumin on glycemic control and lipid profiles among patients with metabolic syndrome and related disorders: a systematic review and metaanalysis of randomized controlled trials," Current Pharmaceutical Design, vol. 24, no. 27, pp. 3184-3199, 2018.

[119] J.-N. Ho, J. Y. Jang, H.-G. Yoon et al., “Anti-obesity effect of a standardised ethanol extract from Curcuma longa L. fermented with Aspergillus oryzae in ob/ob mice and primary mouse adipocytes," Journal of the Science of Food and Agriculture, vol. 92, no. 9, pp. 1833-1840, 2012.

[120] G. Appendino, G. Belcaro, U. Cornelli et al., "Potential role of curcumin phytosome (Meriva) in controlling the evolution of diabetic microangiopathy. A pilot study," Panminerva Medica, vol. 53, no. 3 Suppl 1, pp. 43-49, 2011.

[121] T.-S. Kam, C.-Y. Wong, P.-L. Kwan et al., "Effects and mechanism of turmeric vasorelaxation of the thoracic aorta in hypercholesterolemic rats," Journal of Medicinal Food, vol. 15, no. 2, pp. 190-199, 2012.

[122] S. V. Nampoothiri, E. K. Praseetha, V. V. Venugopalan, and A. Nirmala Menon, "Process development for the enrichment of curcuminoids in turmeric spent oleoresin and its inhibitory potential against LDL oxidation and angiotensinconverting enzyme," International Journal of Food Sciences and Nutrition, vol. 63, no. 6, pp. 696-702, 2012.

[123] G. Kapakos, V. Youreva, and A. K. Srivastava, "Cardiovascular protection by curcumin: molecular aspects," Indian Journal of Biochemistry \& Biophysics, vol. 49, no. 5, pp. 306-315, 2012.

[124] A. M. Gorabi, S. Hajighasemi, N Kiaie et al., "Anti-fibrotic effects of curcumin and some of its analogues in the heart," Heart Failure Reviews, 2019.

[125] P. Y. Liu, "Curcumin: another potential translational candidate for anti-fibrosis on heart failure?" Acta Cardiologica Sinica, vol. 30, no. 5, pp. 483-484, 2014.

[126] H. Li, A. Sureda, H. P. Devkota et al., "Curcumin, the golden spice in treating cardiovascular diseases," Biotechnology Advances, vol. 38, p. 107343, 2020.

[127] S. Saraf-Bank, A. Ahmadi, Z. Paknahad, M. Maracy, and M. Nourian, "Effects of curcumin on cardiovascular risk factors in obese and overweight adolescent girls: a randomized clinical trial," Sao Paulo Medical Journal, vol. 137, no. 5, pp. 414-422, 2019.
[128] A. Saeidinia, F. Keihanian, A. E. Butler, R. K. Bagheri, S. L. Atkin, and A. Sahebkar, "Curcumin in heart failure: a choice for complementary therapy?" Pharmacological Research, vol. 131, pp. 112-119, 2018.

[129] T. Farkhondeh and S. Samarghandian, "Antidotal effects of curcumin against agents-induced cardiovascular toxicity," Cardiovascular \& Hematological Disorders-Drug Targets, vol. 16, no. 1, pp. 30-37, 2016.

[130] A. Hosseini and H. Hosseinzadeh, "Antidotal or protective effects of Curcuma longa (turmeric) and its active ingredient, curcumin, against natural and chemical toxicities: a review," Biomedicine \& Pharmacotherapy, vol. 99, pp. 411-421, 2018.

[131] V. Soleimani, A. Sahebkar, and H. Hosseinzadeh, "Turmeric (Curcuma longa) and its major constituent (curcumin) as nontoxic and safe substances: review," Phytotherapy Research, vol. 32, no. 6, pp. 985-995, 2018.

[132] R. Bahramsoltani, R. Rahimi, and M. H. Farzaei, "Pharmacokinetic interactions of curcuminoids with conventional drugs: a review," Journal of Ethnopharmacology, vol. 209, pp. 1-12, 2017.

[133] M. Sun, X. Su, B. Ding et al., "Advances in nanotechnologybased delivery systems for curcumin," Nanomedicine, vol. 7, no. 7, pp. 1085-1100, 2012.

[134] V. S. Gota, G. B. Maru, T. G. Soni, T. R. Gandhi, N. Kochar, and M. G. Agarwal, "Safety and pharmacokinetics of a solid lipid curcumin particle formulation in osteosarcoma patients and healthy volunteers," Journal of Agricultural and Food Chemistry, vol. 58, no. 4, pp. 2095-2099, 2010.

[135] N. Ahmad, I. Ahmad, S. Umar, Z. Iqbal, M. Samim, and F. J. Ahmad, "PNIPAM nanoparticles for targeted and enhanced nose-to-brain delivery of curcuminoids: UPLC/ESIQ-ToF-MS/MS-based pharmacokinetics and pharmacodynamic evaluation in cerebral ischemia model," Drug Delivery, vol. 23, no. 7, pp. 2095-2114, 2016.

[136] P. A. Subramani, K. Panati, V. R. Lebaka, D. D. Reddy, and V. R. Narala, "Nanostructures for curcumin delivery: possibilities and challenges," Nano- and Micro-scale Drug Delivery Systems, pp. 393-418, Elsevier, Amsterdam, Netherlands, 2017.

[137] H. Ohori, H. Yamakoshi, M. Tomizawa et al., "Synthesis and biological analysis of new curcumin analogues bearing an enhanced potential for the medicinal treatment of cancer," Molecular Cancer Therapeutics, vol. 5, no. 10, pp. 2563-2571, 2006.

[138] T. H. Kim, H. H. Jiang, Y. S. Youn et al., "Preparation and characterization of water-soluble albumin-bound curcumin nanoparticles with improved antitumor activity," International Journal of Pharmaceutics, vol. 403, no. 1-2, pp. 285291, 2011.

[139] Y. Gao, Z. Li, M. Sun et al., "Preparation and characterization of intravenously injectable curcumin nanosuspension," Drug Delivery, vol. 18, no. 2, pp. 131-142, 2011. 